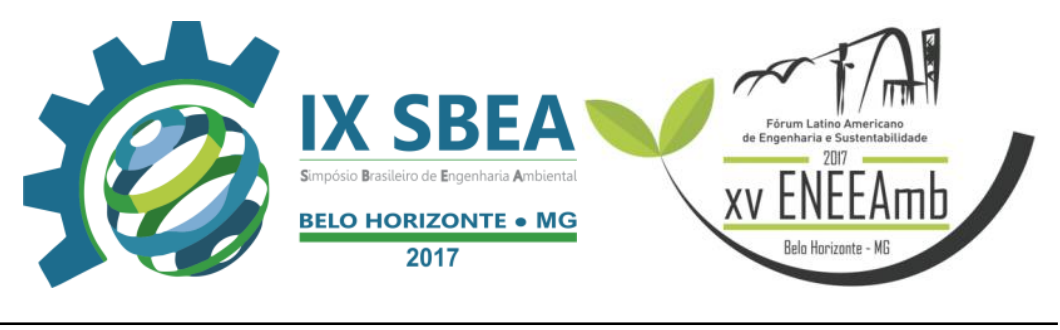

ÁREA TEMÁTICA: RECURSOS HÍDRICOS E SANEAMENTO

\title{
UTILIZAÇÃO DE MÉTODOS BIOLÓGICOS, FÍSICOS E QUÍMICOS NA AVALIAÇÃO DA QUALIDADE DAS ÁGUAS DO RIO VIEIRA, MONTES CLAROS, MG
}

Fernanda Silva Aguiar - fernandaaguiarmel@ hotmail.com

Faculdades Santo Agostinho - FASA de Montes Claros - MG

Ozanan de Almeida Dias - ozanandias@ gmail.com

Faculdades Santo Agostinho - FASA de Montes Claros - MG

Thainá de Paula Cacique e Silva - thainakacique@ hotmail.com

Faculdades Santo Agostinho - FASA de Montes Claros - MG

Vitor Hugo Silva Veloso - vitordakar123@ hotmail.com

Faculdades Santo Agostinho - FASA de Montes Claros - MG

Paulo Adriano Catulé Lima - pauloadrianocatule@ gmail.com

Faculdades Santo Agostinho - FASA de Montes Claros - MG 


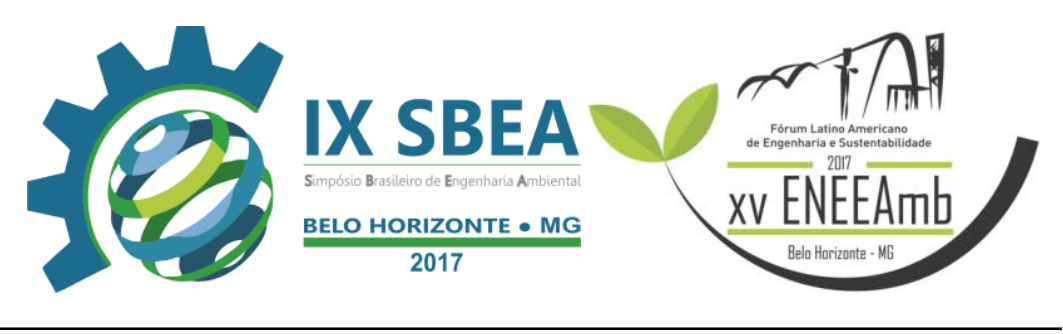

\section{RESUMO}

Tradicionalmente o diagnóstico da qualidade ambiental dos rios é realizado através de análises químicas, físicas e microbiológicas da água, entretanto, essas variáveis retratam a situação momentânea do ecossistema. Diante do exposto, objetivouse nesse trabalho a avaliação da qualidade ambiental das águas do rio Vieira, localizado em Montes Claros - MG, de modo a construir o seu diagnóstico ambiental. No estudo foi escolhido um conjunto de metodologias de avaliação de corpos d'água, buscando a correlação entre os resultados obtidos nos seguintes métodos: Protocolo de Avaliação Rápida de Rios - PAR, métodos analíticos físico-químicos da água e utilização de bioindicadores ambientais. Os resultados das análises físico-químicas indicam o nível acentuado da degradação do rio Vieira, causada pelo despejo de poluentes orgânicos no curso d'água. Na avaliação dos bioindicadores foram identificados 4319 indivíduos num conjunto de 12 táxons, sendo predominante a ordem da Diptera, bem como a de Pulmonata. As famílias Chironomidae, pertencentes à ordem Diptera, predominaram na maioria dos pontos amostrais, principalmente nos pontos B e C que estão localizados na área urbana de Montes Claros. Os resultados integrados de diferentes métodos permitiram uma visão ampla do ecossistema estudado, trazendo importantes informações a respeito da integridade ecológica e da qualidade das águas do recurso hídrico estudado.

Palavras-chave: Diagnóstico Ambiental, Biondicadores, Avaliação Físico-químicas.

\section{INTRODUÇÃO/OBJETIVO}

A idéia de que a água seja um recurso infinito, foi substituído pela percepção de que o modelo atual de desenvolvimento econômico, em detrimento dos recursos naturais, levará o Brasil à escassez hídrica. De acordo com Fia et al. (2015) os rios urbanos têm sido transformados, perdendo suas características naturais, afetando diretamente a qualidade de suas águas, devido à expansão econômica, sobre tudo, em decorrência do elevado crescimento demográfico.

Os recursos hídricos vêm sofrendo fortes pressões antropogênicas, que por consequência trazem diversos danos ambientais, levando a preocupação no que diz respeito à disponibilidade de água em padrões de qualidade. Essa situação é observada 


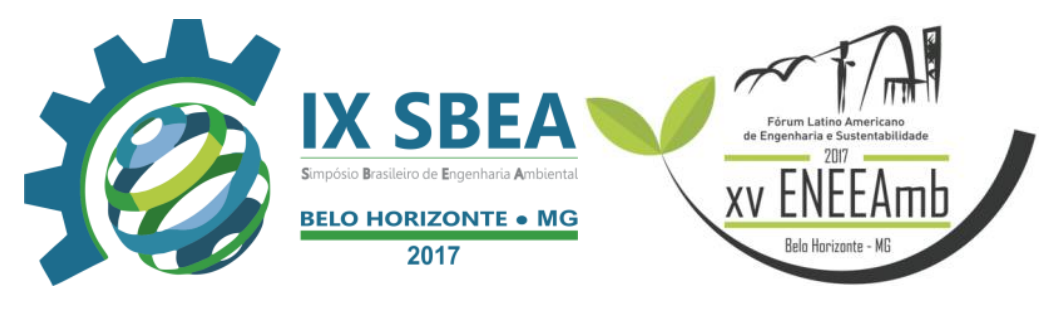

em áreas urbanas localizadas às margens de rios, onde ocorrem os lançamentos de esgotos, efluentes industriais e resíduos sólidos no corpo d'água, resultando impactos ambientais alarmantes (CALLISTO \& MORENO, 2006).

Mediante o contexto é de suma importância a avaliação da qualidade ambiental dos corpos d'águas. O diagnóstico ambiental tem sido realizado através de análises químicas, físicas e microbiológicas da água. Entretanto, essas variáveis retratam a situação momentânea do ecossistema, é ideal que a essas metodologias sejam empregados métodos biológicos na avaliação, permitindo um diagnóstico ambiental mais preciso (CALLISTO et al., 2004).

Nesse sentido, tem-se utilizados os bioindicadores, que são espécies cuja presença, diversidade e abundância indicam a magnitude dos impactos ambientais em um ecossistema aquático. Salientam Hepp \& Restello (2007) que os macroinvertebrados possuem uma série de vantagens, dentre elas: facilmente amostrados; fácil visualização e identificação; sensíveis a modificações em seu habitat; baixa variabilidade genética e ecológica, sendo sensível a contaminações não detectáveis por métodos físico-químicos.

Diante de todo o exposto, objetivou-se nesse trabalho a avaliação da qualidade ambiental das águas do rio Vieira, de modo a construir o seu diagnóstico ambiental. Além disso, pretende-se compreender a relação da urbanização com a qualidade ambiental do recurso hídrico estudado. A avaliação busca traçar o perfil da qualidade das águas do rio, utilizando diferentes métodos de análises.

\section{METODOLOGIA}

$\mathrm{O}$ rio Vieira, objeto deste estudo de pesquisa, constitui a principal bacia hidrográfica do município de Montes Claros, norte de Minas Gerais. Nesse rio foram selecionados 07 pontos no curso principal (Figura 1), indicando a situação ambiental à montante da urbanização - ponto A, na área urbanizada - pontos B e C, à jusante da urbanização - pontos D e E, e na foz do rio Vieira - pontos F e G.

No estudo foi escolhido um conjunto de metodologias de avaliação de corpos d'água, buscando a correlação entre os resultados dos seguintes métodos: Protocolo de Avaliação Rápida de Rios - PAR, métodos analíticos físico-químicos da água e utilização de bioindicadores ambientais. As coletas ocorreram nos dias 26 e 27 de 


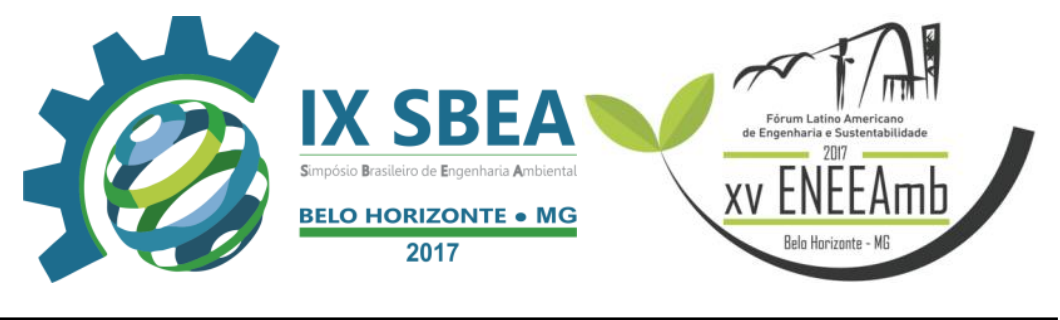

setembro de 2015, na estação seca, em um período de estiagem prolongada no Norte de Minas.

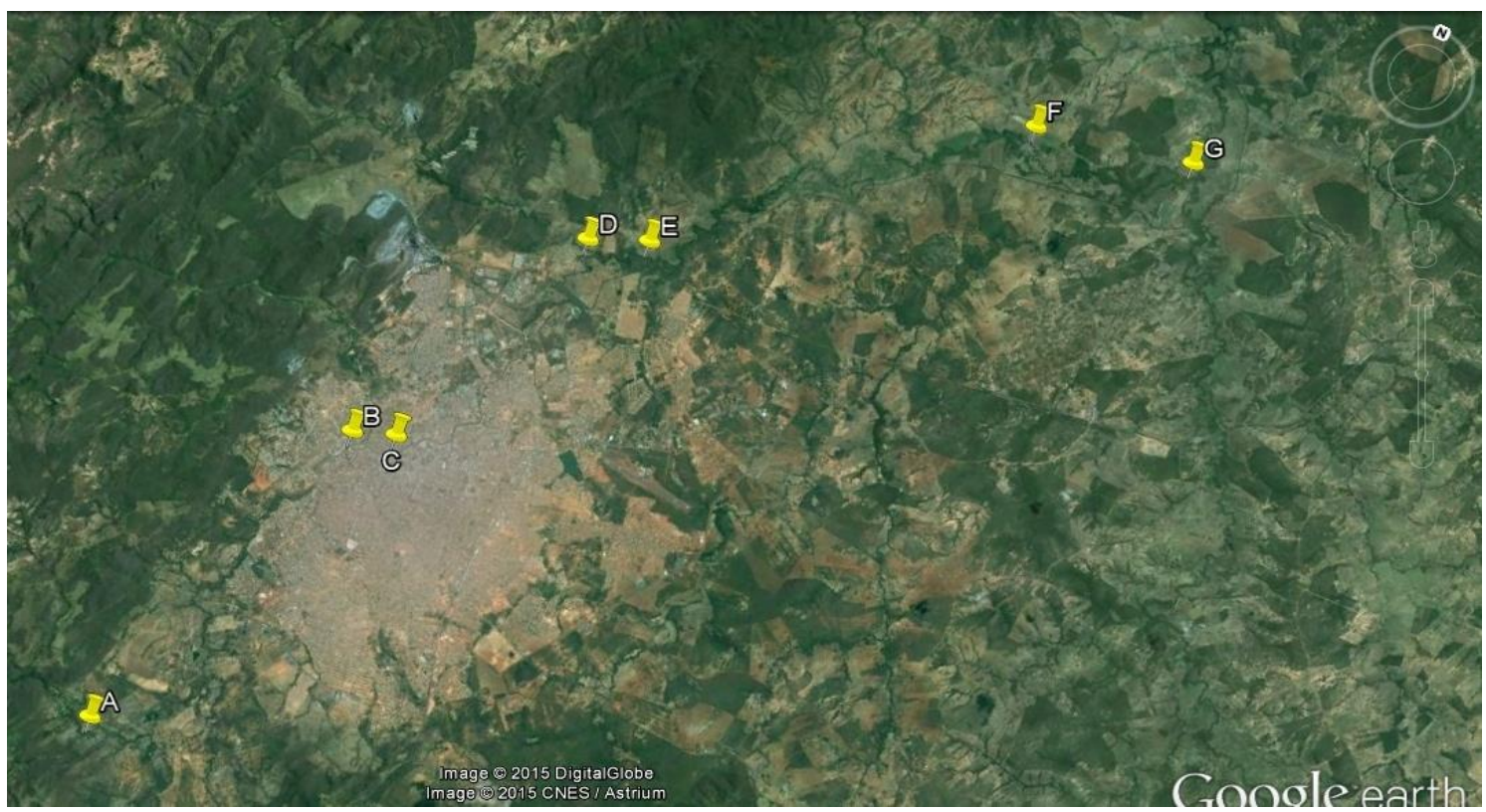

Figura 1 - Pontos de amostragem no rio Vieira.

Fonte: Adaptado da imagem do Google Earth, 2015.

O PAR utilizado nesse estudo, modificado da proposta original de Hannaford et al. (1997) e da Agência de Proteção Ambiental de Ohio (EUA) EPA (1987), foi proposto por Callisto et al. (2001). O protocolo é constituído de um Checklist de duas partes, formando um conjunto de 22 parâmetros. Com base nos valores atribuídos a cada um dos parâmetros obtém-se a pontuação final, classificando os trechos estudados conforme a sua situação ambiental (CALLISTO et al., 2001).

No que concerne às avaliações físico-químicas, coletou-se a água do rio Vieira para análises dos seguintes parâmetros: temperatura $\left({ }^{\circ} \mathrm{C}\right), \mathrm{pH}(-)$, oxigênio dissolvido ( $\mathrm{mg} \mathrm{L}^{-1}$ de $\mathrm{O}_{2}$ ), turbidez (N.T.U), nitrogênio amoniacal ( $\mathrm{mg} \mathrm{L}^{-1}$ de $\mathrm{NH}_{3}$ ) e ortofosfato $\left(\mathrm{mg} \mathrm{L}^{-1}\right.$ de $\left.\mathrm{PO}_{4}\right)$. As análises da água foram feitas em campo através do EcoKit Técnico - Educação Ambiental Cód. 6682.

Associado a PAR e as análises físico-químicas, foi realizado a avaliação dos macroinvertebrados bentônicos, bioindicadores da qualidade ambiental de ecossistemas 


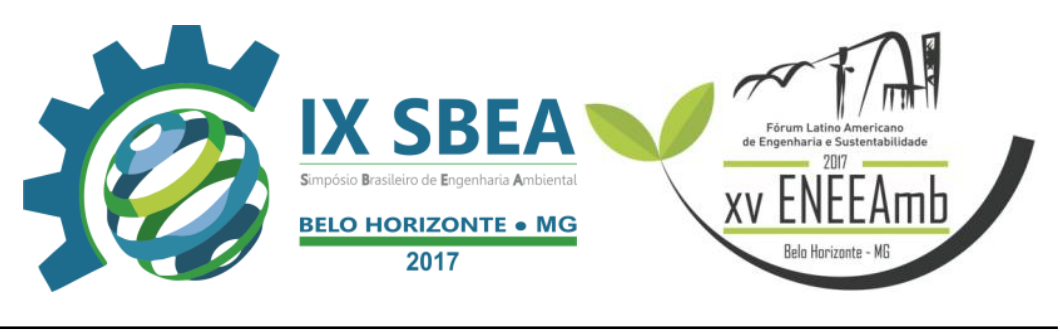

aquáticos. Nesse estudo as espécies encontradas foram divididas em três grupos: organismos sensíveis ou intolerantes (Trichoptera, Plecoptera, Ephemeroptera), organismos tolerantes (Coleoptera, Heteroptera, Odonata) e organismos resistentes (Diptera, Oligochaeta) (CALLISTO et al., 2004).

Para as amostras dos macroinvertebrados bentônicos, empregou-se a metodologia mencionada por Merritt \& Cummins (1996), utilizando-se um amostrador tipo Surber de área $0,1 \mathrm{~m}^{2} \mathrm{com}$ malha de $250 \mu \mathrm{m}$. Em cada ponto foi realizado duas coletas, uma na margem esquerda e outra na margem direita, perfazendo um total de 14 amostras. Os frascos com as amostras dos macroinvertebrados foram encaminhados para o Laboratório de Ecologia e Controle Biológico de Insetos do Departamento de Biologia Geral da Universidade Estadual de Montes Claros - UNIMONTES, campus Montes Claros - MG, para serem identificados por especialistas.

\section{RESULTADOS E DISCUSSÃO}

Os resultados apresentados na aplicação do PAR no rio Vieira classificaram os trechos A e $\mathrm{G}$ como naturais. Os pontos $\mathrm{B}$ e $\mathrm{F}$ foram identificados como alterados, e os demais, C, D e E foram enquadrados como impactados. Percebe-se que as piores pontuações foram atribuídas aos pontos localizados na área urbana e à jusante da urbanização. Nos trechos B e C, verifica-se que a retificação e encaixotamento do curso d'água foram decisivos para o resultado obtido.

Situações semelhantes foram obtidas por Rodrigues et al. (2008) que analisaram, através do PAR, a qualidade ambiental de rios na região de Ouro Preto - MG. Comentam os autores, que as condições ambientais mais severas foram encontradas nas áreas urbanas, onde evidenciaram a ausência das matas ciliares, além de vários pontos de lançamento de esgotos doméstico ao longo do curso d'água.

Os resultados das análises dos parâmetros físico-químicos (Tabela 1) demonstraram que as temperaturas das águas do rio variaram de 21 a $28^{\circ} \mathrm{C}$, sendo as menores temperaturas obtidas nos trechos A e B. Os resultados indicam a hipótese de que o lançamento de poluentes orgânicos, assim como a supressão da vegetação das margens do Vieira foram fatores que contribuíram para elevação da temperatura das águas. 


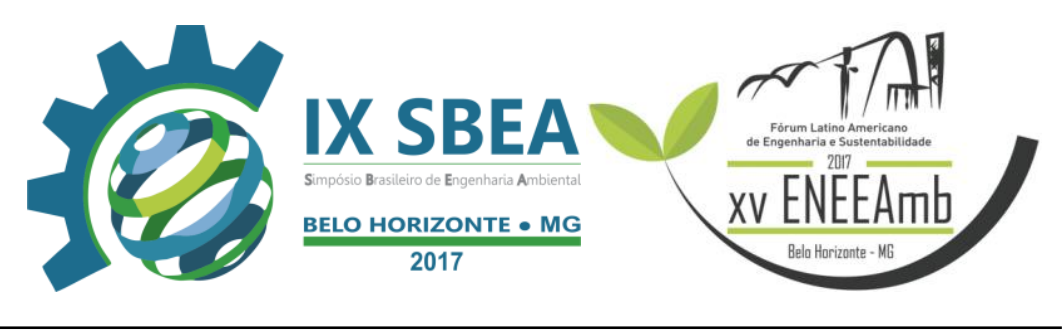

Tabela 1 - Resultados das análises físico-químicas da água do rio Vieira.

\begin{tabular}{|l|c|c|c|c|c|c|c|}
\hline \multicolumn{7}{|c|}{ Resultado das amostras e outras informações ecológicas } \\
\hline \multicolumn{1}{|c|}{ Trechos } & A & B & C & D & E & F & G \\
\hline Largura do canal do rio $(\mathrm{m})$ & 3,5 & 3,2 & 7,0 & 3,0 & 3,0 & 5,5 & 4,0 \\
\hline Altura da lâmina d'água (m) & 0,5 & 0,1 & 0,15 & 0,7 & 0,5 & 0,4 & 0,6 \\
\hline Velocidade da correnteza $\left(\mathrm{m} \mathrm{s}^{-1}\right)$ & 0,1 & 0,35 & 1,05 & 0,6 & 0,8 & 0,3 & 0,23 \\
\hline Temperatura da água $\left({ }^{\circ} \mathrm{C}\right)$ & 21,0 & 23,0 & 28,0 & 26,0 & 28,0 & 26,0 & 26,0 \\
\hline Oxigênio dissolvido $\left(\mathrm{mg} \mathrm{L}^{-1}\right)$ & 8,0 & 7,0 & 5,0 & 1,0 & 1,0 & 5,0 & 5,0 \\
\hline pH $(-)$ & 7,5 & 8 & 7,5 & 7 & 8 & 7,5 & 7,5 \\
\hline Nitrogênio amoniacal $\left(\mathrm{mg} \mathrm{L}^{-1}\right)$ & 0,3 & 3,6 & 3,6 & 3,6 & 3,6 & 3,6 & 3,6 \\
\hline Ortofosfato (mg L $\left.{ }^{-1}\right)$ & 0,0 & 2,5 & 3,0 & 3,0 & 3,0 & 3,0 & 3,0 \\
\hline Turbidez $(\mathrm{NTU})$ & $<50$ & $<50$ & $50>100$ & $50>100$ & $50>100$ & $<50$ & $<50$ \\
\hline
\end{tabular}

Fonte: Próprios autores.

Verifica-se por meio das análises que a temperatura não exerceu influência significativa nos resultados do oxigênio dissolvido - OD. A oscilação a partir do ponto B foi de $2^{\circ} \mathrm{C}$, apesar disso as variações do oxigênio foram amplas. O oxigênio é um fator limitante para manutenção da vida aquática, seu valor mínimo preconizado pela Resolução CONAMA n ${ }^{\circ} 357 / 05$ é de $5 \mathrm{mg} \mathrm{L}^{-1}$. Somente os pontos amostrais A e B apresentaram valores de OD acima do limite mínimo determinado pela resolução, indicando que as águas do rio Vieira possuem baixa oxigenação.

Nos pontos D e E foram identificada concentrações de $1 \mathrm{mg} \mathrm{L}^{-1}$ de OD, onde constatou-se um despejo maior de carga orgânica. Já nos pontos $F$ e $G$ localizados próximo a foz do Vieira foram encontrados $5 \mathrm{mg} \mathrm{L}^{-1}$ de $\mathrm{OD}$, contudo não consegue alcançar valores para atingir a zona de águas limpas antes da confluência do rio.

No que diz respeito ao pH, a Resolução CONAMA n 357/2005 estabelece uma faixa limite de 6 a 9 para os cursos d'água enquadrados como classe 2. Os resultados de pH encontrados não apresentaram grandes variações, os valores oscilaram entre 7 a 8 , registrando média igual 7,57. O pH observado apresentou águas com características variando de básicas a ligeiramente alcalinas. 


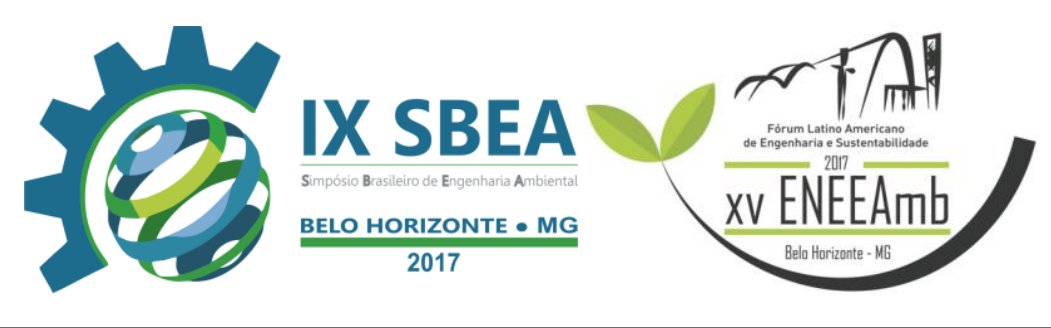

Para o nitrogênio amoniacal, a Resolução CONAMA no 357/05 estabelece limites variáveis de acordo com os valores de $\mathrm{pH}\left(3,7 \mathrm{mg} \mathrm{L}^{-1}\right.$ para $\mathrm{pH}$ menor ou igual a 7,5; $2 \mathrm{mg} \mathrm{L}^{-1}$ para $\mathrm{pH}$ entre 7,5 e 8,0;1 $\mathrm{mg} \mathrm{L}^{-1}$ para $\mathrm{pH}$ entre 8 e 8,5; e $0,5 \mathrm{mg} \mathrm{L}^{-1}$ para $\mathrm{pH}$ acima de 8,5) (BRASIL, 2005). Considerando os valores de $\mathrm{pH}$ encontrados nos pontos amostrais, constata-se que os trechos B e E estão fora dos padrões. O limite máximo fixados pelo CONAMA para corpos d'água classe 2, é de $1 \mathrm{mg} \mathrm{L}^{-1}$ de $\mathrm{NH}_{3}$, porém os resultados apresentaram concentrações de $3,6 \mathrm{mg} \mathrm{L}^{-1}$ de $\mathrm{NH}_{3}$.

Se referindo ao parâmetro ortofosfato, as águas do rio Vieira obtiveram resultados elevados, exceto o trecho A que apresentou um valor baixo. Os valores oscilaram entre 2,5 a 3,0 mg L $\mathrm{L}^{-1}$. O fósforo nos recursos hídricos tem origem natural e antropogênica, a primeira resulta de compostos no solo e decomposição da matéria orgânica, já os de procedências humanas incluem-se os esgotos domésticos, efluentes industriais, detergentes e fertilizantes lançados nos corpos d'água (VON SPERLING, 2014).

Em um estudo realizado nas águas do Vieira por Borges (2007) foi encontrado altas concentrações de fósforo. Segundo a autora, em uma de suas campanhas os resultados variaram de 1,09 a $6,13 \mathrm{mg} \mathrm{L}^{-1}$ em pontos de coleta localizados na urbanização, à jusante da cidade de Montes Claros e próximos à foz. Os resultados dos nutrientes fósforo e nitrogênio encontrados são preocupantes. É previsível a formação do quadro de eutrofização, devido os elevados teores de fosfato, nitrogênio amoniacal e matéria orgânica, provenientes do esgoto doméstico e industrial que são despejados nas águas do rio Vieira sem tratamento adequado.

No que se concerne a turbidez os valores determinados pela Resolução CONAMA n 357 para águas classe 2 é de no máximo 100 UNT. Os valores encontrados nos pontos de amostragem não ultrapassam o limite máximo. Haja vista que as coletas das águas ocorreram na estação seca, em um período de grande estiagem, houve um decaimento da turbidez das águas do rio Vieira.

$\mathrm{Na}$ avaliação do parâmetro biológico (Tabela 2), foram identificados 4319 macroinvertebrados bentônicos nos pontos amostrais do rio Vieira, num conjunto de 12 táxons, sendo predominante o grupo de Diptera, bem como o de Pulmonata, grupo característico de ambientes com grande quantidade de matéria orgânica. 


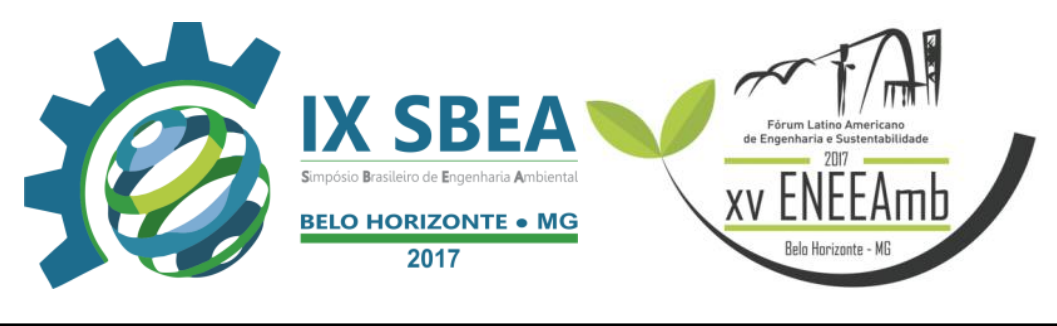

Tabela 2 - Resultado dos invertebrados bentônicos e valor de tolerância à poluição.

\begin{tabular}{|c|c|c|c|c|c|c|c|c|c|}
\hline \multicolumn{2}{|c|}{ Táxons } & $\mathrm{A}$ & B & $\mathrm{C}$ & $\mathrm{D}$ & $\mathrm{E}$ & $\mathrm{F}$ & $\mathrm{G}$ & VTP* \\
\hline Ephemeroptera & Leptophlebiidae & 30 & - & - & - & - & - & - & $\mathrm{N}^{*}$ \\
\hline Diptera & Chironomidae & 19 & 3437 & 221 & 5 & 12 & 420 & 48 & 7 \\
\hline \multirow[t]{3}{*}{ Coleoptera } & Elmidae & 1 & - & - & - & - & - & - & 4 \\
\hline & Dytiscidae & - & - & - & - & - & - & 1 & $\mathrm{~N}$ \\
\hline & Gyrinidae & - & - & - & - & - & 1 & 11 & $\mathrm{~N}$ \\
\hline \multirow[t]{4}{*}{ Odanata } & Aeshnidae & 2 & - & - & - & - & - & - & $\mathrm{N}$ \\
\hline & Libellulidae & 2 & - & - & - & - & - & - & $\mathrm{N}$ \\
\hline & Gomphidae & 12 & - & - & - & - & - & - & 4 \\
\hline & Perilestidae & 2 & - & - & - & - & - & - & $\mathrm{N}$ \\
\hline \multirow[t]{2}{*}{ Annelida } & Oligochaeta & 3 & - & - & - & - & - & - & 8 \\
\hline & Empididae & - & - & 6 & 6 & - & - & - & $\mathrm{N}$ \\
\hline Pulmonata & Gastrópode & 7 & 60 & 11 & 1 & - & 5 & 3 & 7 \\
\hline \multicolumn{2}{|c|}{ Total de indivíduos } & 78 & 3497 & 238 & 12 & 12 & 426 & 63 & \\
\hline
\end{tabular}

VTP - valor de tolerância à poluição. VTP $=0$ a 3 não tolerantes a poluição; VTP $=4$ a 5 tolerantes a moderada poluição; VTP $=6$ a 10 muito tolerantes a poluição.

$\mathrm{N}$ - Não foi possível identificar o VTP.

Fonte: Próprios autores.

O número grande de indivíduos encontrados nas águas do rio Vieira tem relação direta com a estação seca. Em períodos de estiagem o ambiente torna-se mais estável, favorecendo o estabelecendo comunidades bentônicas e elevação da densidade. As famílias Chironomidae, pertencentes à ordem Diptera, predominaram na maioria dos pontos amostrais, principalmente nos pontos B e C que estão localizados na área urbana de Montes Claros. Esses bioindicadores possuem alta tolerância à poluição, VTP igual a 7, correspondem a 96,36\% de todos os indivíduos encontrados no rio Vieira.

De acordo com Goulart \& Callisto (2003) as larvas de Chironomidae são extremamente tolerantes a poluição orgânica, sendo capazes de viver em condições anóxias por várias horas, além de serem espécies detritívoras, ou seja, se alimenta de matéria orgânica, o que favorece a sua proliferação em ambientes poluídos.

Os resultados demonstram condizentes com as análises físico-químicas, onde foram encontrados valores elevados de nitrogênio amoniacal e ortofosfato nos pontos 


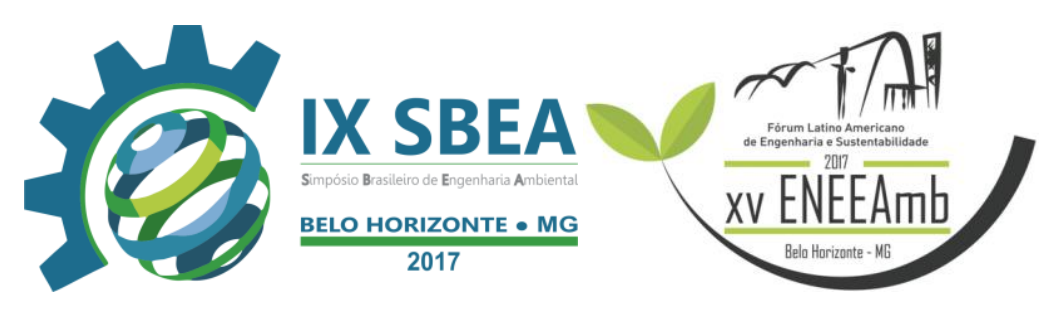

amostrais $\mathrm{B}$ e $\mathrm{C}$, onde o rio Vieira tem sido, sobremaneira, impactado por esgotos domésticos e efluentes indústrias lançados no curso d'água.

No que se referem os gastrópodes, também nos trechos $\mathrm{B}$ e $\mathrm{C}$ foram encontrados maior número de indivíduos, representando cerca de $1,85 \%$ de todos os macroinvertebrados identificados. Nas análises físico-químicas, os valores de $\mathrm{pH}$ demonstraram que as águas do rio Vieira apresentam características básicas a ligeiramente alcalinas, o que pode ter propiciado a predominância dos Gastrópodes.

A maior diversidade de macroinvertebrados identificados nas águas do rio Vieiras ocorreu no ponto amostral A, localizado a montante da área urbanizada. Sendo o único local em que foram coletadas espécies da família Ephemeropta, insetos aquáticos intolerantes à poluição. Portanto, isso confirma uma situação ambiental melhor no Vieira a montante da urbanização. Essa afirmativa é corroborada pelos resultados do Protocolo de Avaliação Rápida de Rios - PAR e das análises físico-químicas da água. Os resultados da análise estavam dentro padrões estabelecidos pela Resolução CONAMA $n^{\circ} 357 / 2005$, além do mais, o trecho A foi enquadrado como natural na aplicação do PAR.

Resultados semelhantes Bueno et al. (2003) encontraram em um estudo de dois corpos d'água no Rio Grande do Sul, segundo os autores a maior abundância e riqueza de macroinvertebrados foram devido ao maior grau de preservação do ambiente, além de maior cobertura vegetal do trecho amostrado, o que produz uma grande quantidade folhiço, servindo de alimento e abrigo para muitas larvas de insetos.

No que diz respeito aos pontos $\mathrm{D}$ e E, esses apresentaram poucos indivíduos das ordens Pulmonata e Diptera, apesar de serem respectivamente macroinvertebrados resistentes à poluição ambiental. Tudo indica que as características ecológicas do curso d'água, assim como peculiaridades físicas e químicas da água nesses pontos não favorecem a estruturação de comunidades bentônicas.

$\mathrm{O}$ ponto $\mathrm{G}$ teve uma pequena melhora, tendo em vista o número reduzido de táxons de Diptera e Gastrópode encontrado, no entanto as condições ambientais do rio Vieira ainda não continuam favoráveis para existência de bioindicadores sensíveis a poluição ambiental. 


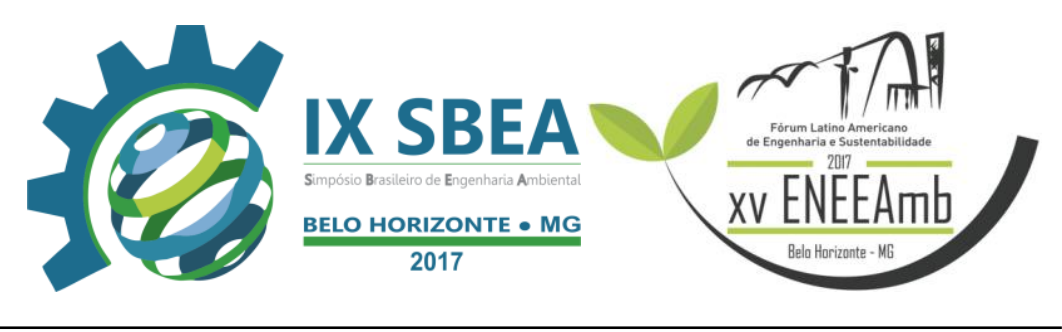

\section{CONCLUSÕES/RECOMENDAÇÕES}

O uso das diferentes metodologias, Protocolo de Avaliação Rápida de Rios, bioindicadores ambientais e métodos analíticos físico-químicos foram satisfatórios para a investigação dos efeitos da urbanização sobre a qualidade ambiental do rio Vieira.

Concluiu-se que a qualidade das águas e a situação ambiental do rio Vieira decrescem a partir do ponto localizado à montante da urbanização, caindo bruscamente quando o curso d'água percorre a cidade de Montes Claros.

Pode-se inferir que o período de estiagem prolongada no Norte de Minas foi determinante para os resultados encontrados, principalmente nas análises físicoquímicas e do levantamento de macroinvertebrados bioindicadores da qualidade ambiental do rio Vieira. Diante disso, recomenda-se que seja realizada uma nova campanha de amostragens na estação chuvosa, comparando com os resultados encontrados no presente trabalho.

A partir dos resultados encontrados, verifica-se a necessidade de adotar medidas que visem mitigar ou eliminar a degradação ambiental do rio Vieira, a começar pela gestão integrada dos recursos hídricos. Essa ação abrangeria diversos temas, como a criação de políticas públicas, planejamento territorial urbano, projetos de educação ambiental e outras iniciativas voltadas às bacias hidrográficas de Montes Claros.

\section{REFERÊNCIAS BIBLIOGRÁFICAS}

BRASIL. Resolução do Conselho Nacional do Meio Ambiente - CONAMA n ${ }^{\circ} 357$, de 17 de março de 2005. Dispõe sobre a classificação dos corpos de água e diretrizes ambientais para o seu enquadramento, bem como estabelece as condições e padrões de lançamento de efluentes, e dá outras providências. Diário Oficial da Republica Federativa do Brasil, Brasília, DF, 18 de mar. 2005. Disponível em: http://www.mma.gov.br/port/conama/res/res05/res35705.pdf. Acesso em: 30/05/2017.

BORGES, L. Qualidade da água do rio Vieira sob a influência da área urbana de Montes Claros. Minas Gerais, 2007. 98p., Dissertação (Mestrado em Engenharia Civil) - Universidade Federal de Uberlândia, 2007. 


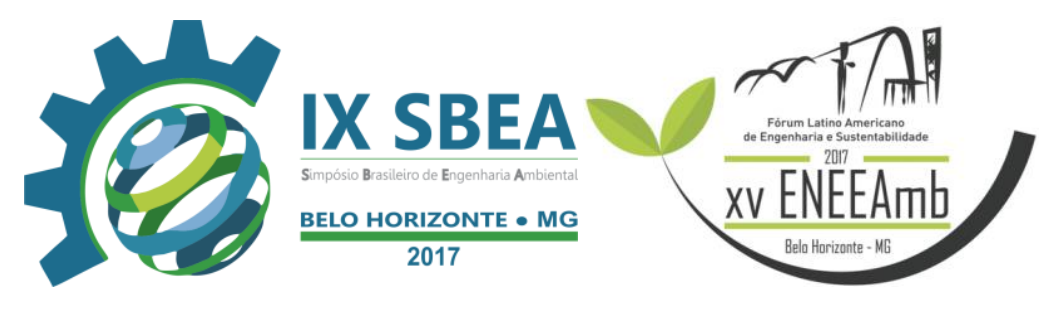

BUENO, A. A. P.; BUCKUP, G. B.; FERREIRA, B. P. Estrutura da comunidade de invertebrados bentônicos em dois cursos d'água do Rio Grande do Sul, Brasil. Revista. Brasil. Zoologia, Curitiba, v. 20, n. 1, p. 115-125, 2003.

CALLISTO, M; MORENO, P.; BARBOSA, F. A. R. Habitat diversity and benthic functional trophic groups at Serra do Cipó. Revista Brasileira de Biologia, São Carlos, v. 61, p. 259-266, 2001.

CALLISTO, M.; MORENO, P. Bioindicadores como ferramenta para o manejo, gestão e conservação ambiental In: SIMPÓSIO SUL DE GESTÃO E CONSERVAÇÃO AMBIENTAL, 2., 2006, Erechim. Anais... Erechim: URI-Campus de Erechim, 2006. P.322-333.

CALLISTO, M; GONÇALVES, JR.; MORENO, P. Invertebrados aquáticos como bioindicadores. In: Navegando o rio das velhas das Minas aos Gerais. Belo Horizonte: UFMG, Universidade Federal de Minas Gerais, 2004. p. 1-12.

FIA R.; TADEU H.C.; MENEZES, J. P. C; FIA, F. R. L; OLIVEIRA, L. F. C. Qualidade da água de um ecossistema lótico urbano. Revista Brasileira de Recursos Hídricos, Porto Alegre, v. 20, n. 2, p. 267-275, 2015.

GOUlART, M. D., CALliSTO, M. Bioindicadores de qualidade de água como ferramenta em estudos de impacto ambiental. Revista FAPAM, Pará de Minas, v. 2, n. 1, p. 156-164, 2003.

HANNAFORD, M. J.; BARBOUR, M. T.; RESH, V. H. Training reduces observer variability in visual-based assessments of stream habitat. Journal of the North American Benthological Society, v. 16, n. 4, p. 853-860, 1997.

HEPP, L. U. ; RASTELO, R. M. Macroinvertebrados bentônicos como bioindicadores da qualidade das águas do AltuUrucuia Gaúcho. In: CONSERVAÇÃO E USO SUSTENTÁVEL DA ÁGUA: MÚLTIPLOS OLHARES, Erechim. Anais... Erechim: URI - Campus de Erechim, 2007. p. 75-85.

MERRITT, R. W.; CUMMINS. K. W. An introduction to the aquatic insects of North America, $3^{\circ}$ ed. Dubuque, IA: Editora Kendall/Hunt Publishing, 1996. 862 p.

RODRIGUES, A. S. L.; MALAFAIA, G.; CASTRO, P. T. A. Avaliação ambiental de trechos de rios na região de Ouro Preto - MG através de um Protocolo de Avaliação Rápida. Revista de Estudos Ambientais, Blumenau, v. 10, n. 1, p. 74-83, 2008.

VON SPERLING, M. Estudos e modelagem da qualidade da água de rios. $2^{\circ}$ ed. Belo Horizonte: Editora UFMG, 2014. 592 p. 